\title{
The relationships between seedling root screens, root growth in the field and grain yield for winter wheat
}

3 C. Bai ${ }^{1}$, Y. Ge ${ }^{1}$, R.W. Ashton ${ }^{1}$, J. Evans ${ }^{1}$, A. Milne ${ }^{1}$, M.J. Hawkesford ${ }^{1}$, W.R. Whalley ${ }^{1}$, M. A.

$4 \quad$ J. Parry ${ }^{2}$, J., Melichar ${ }^{3}$, D. Feuerhelm³ ${ }^{3}$ P., Bansept Basler ${ }^{4}$, M., Bartsch ${ }^{5}$

5

$6 \quad{ }^{1}$ Rothamsted Research, Harpenden, Hertfordshire, AL5 2JQ, United Kingdom

$7{ }^{2}$ Lancaster Environment Centre, Lancaster University, Lancaster, LA1 4YQ,

8 United Kingdom

$9 \quad{ }^{3}$ Syngenta Seeds Ltd., Hill Farm Road, Whittlesford, CB2 4QT, United Kingdom

${ }^{4}$ Syngenta SAS, Avenue Gustave Eiffel, 2800 Chartres, France

${ }^{5}$ Syngenta Crop Protection, Schaffhauserstrasse 101, 4332 Stein, Switzerland

Corresponding author richard.whalley@rothamsted.ac.uk

Background and aims: We were interested to know if laboratory screens of root growth could be used to predict root performance and grain yield of wheat when grown in the field. A secondary aim of this work was to explore the relationship between root depth and grain yield.

Methods: We screened 637 wheat lines, composed of elite as well as a limited number of breeding lines, to identify wheat lines with contrasting young root traits with a high throughput screen. We selected groups of wheat lines based on the size of the seedling root, root diameter and growth angle. Seventy-two wheat lines were subjected to further screening with a wax-layer screen and grown in a field experiment in two successive years. Root length distributions, from field grown wheat, were determined with the core-break method.

Results: We were unable to find relationships between data from the laboratory root screens and root depth in the field. In the field, wheat lines with deep roots always had high grain yields, but deep roots were not essential to obtain high yields. Wheat lines with the deepest roots were also amongst those with the greatest number of shallow roots. 
Conclusion: Laboratory root screens did not predict root depth in the field. Root diameter, for reasons that are not clear, is correlated with high grain yield.

Keywords Wheat, Roots, Laboratory Screens, Root depth, Yield

\section{Introduction}

In the field the root growth environment is complex, deep roots are almost exclusively to be found in pre-existing pores (White and Kirkegaard 2010). Increases in soil strength with depth may be responsible for confining roots to existing pores, especially when penetrometer resistances in the bulk soil are much greater than $2.5 \mathrm{MPa}$ (Gao et al., 2016, Hodgkinson, et al., 2017). The increase in soil strength with depth is a ubiquitous phenomenon due to the increased weight of soil as depth increases and penetrometer resistance can exceed $2.5 \mathrm{MPa}$ at depths as shallow as $50 \mathrm{~cm}$ (Gao et al. 2016). Although field studies have shown that root length density decreases exponentially with depth (e.g. Gerwitz and Page 1974; Fan et al. 2016), this contrasts with many laboratory experiments (e.g. Manschadi et al 2008; Jin et al. 2015; Gao et al. 2016). Differences in pore distribution with depth, and how different genotypes can locate pores, may explain the genetic differences in wheat root distribution with depth. The inability of roots to access water is commonly attributed to a low root length density at depth (Gregory et al. 1978a, b). For this reason, the root depth of wheat in the UK, and elsewhere, has been of considerable interest (e.g. Lupton et al. 1974; Gregory et al. 1978a; Barraclough and Leigh 1984; White et al. 2015; Ober at I. 2014; Wasson et al. 2014; Hodgkinson et al. 2017). However, within wheat lines that are currently grown commercially in the UK, there is recent evidence that some lines are more effective at accessing deep water than others (Whalley et al. 2017).

The complex field environment makes the use of laboratory screens to predict deep or prolific root growth in the field a challenging problem. There has been considerable interest in developing laboratory-based root screens in for example for wheat (Bai et al. 2013; Whalley et al. 2013), rice (Clark et al. 2002), maize (Chimungu et al. 2015) and oil seed rape 
(Thomas et al. 2016) which can provide a rapid laboratory assessment of the potential of deep rooting or indeed any other field performance characteristic. These screens, by necessity, provide a simplified root growth environment. Nevertheless, even relatively simple screens, such as the rolled-paper screen (Bai et al. 2013) have had some success in predicting root depth of wheat in early vegetative growth in the field (Watt et al. 2013). More complex screens, such as the wax-layer screen (Whalley et al. 2013) are designed to replicate hard layers in soil, however, in rice the ability of roots to penetrate strong wax layers does not always identify lines with deep roots in the field (Clark et al. 2002). Thomas et al. (2016) found that high throughput root screens could be used to predict seed yield in oil seed rape. High throughput laboratory screens, based on growing wheat seedlings on sloping filter paper, have found differences in root architecture between wheats with low and high nitrogen uptake efficiency in the field (Kenobi et al. 2017). High through put root screens, based on the use of sloping filter paper, avoid the technical and labour challenges of field-based approaches and advanced mathematical approaches have been developed to interpret such data (e.g. Kalogiros te al. 2016). However, it is important to be able to relate data from high through put root screens to root growth in the field. Especially since White et al. (2015) have shown that in UK conditions higher wheat yields are associated with higher root densities in the surface layer, although the effect of rooting depth on yield was considered to be less important, due to low root densities in deeper layers.

Root traits thought to be associated with deep roots include thick roots, steep roots, roots that resist buckling and root length (Thomas et al, 2016; Steele et al. 2013; Clark et al. 2008; Clark et al. 2002). A motivation to identify roots that can elongate to depth in the field is that deep roots are associated in yield increases (Lynch, 2007, 2011). In this paper, we describe the use of the high throughput rolled-paper screen to characterise the root growth of a large number of wheat lines. These data were used to identify a subset of wheat lines, with contrasting root phenotypes, which were then screened with the wax layer method and grown in two successive years in a field experiment. We compare laboratory screen data with root growth in the field and grain yield. These data provide the opportunity to explore the 
relationships between root depth distribution and grain yield in two seasons with very different rainfall patterns. Furthermore, the field data may also provide an insight into why some wheat lines have deep roots and others do not.

\section{Materials and methods}

\section{Plant material}

An initial set of 637 wheat lines were screened with the high throughput 'cigar roll' system (see below). The initial set of 637 wheat lines was selected, by the Syngenta wheat breeding team, to include representative lines from all the main wheat growing regions of the world as well as including lines know to be high yielding or drought tolerant. Based on these data, 71 lines were selected and screened with the wax layer system and then grown in field experiments in two successive seasons. The choice of 72 lines was based on root diameter, root angle and root length determined in the cigar roll screen, as described in the results section. We also included Rht-B1c Dwarf Mercia (Dwarf) and Rht- B1a Mercia (Tall) near isogenic lines, which had been grown previously on the same field site (Hodgkinson et al. 2017).

\section{Cigar-roll screen}

A screening system based on the 'cigar roll' system was utilised (Zhu et al., 2005; Bai et al.2013). Seeds were surface-sterilized with $0.5 \%$ calcium hypochlorite solution for $30 \mathrm{~min}$ and then rinsed 3 times with sterilised water and left in the cold room $\left(4^{\circ} \mathrm{C}\right)$ over night. Subsequently the seeds were germinated in petri dishes on tissue with sterilised water. Four uniformly germinating seeds were placed on one germination paper $(25 \times 38 \mathrm{~cm}$, Anchor paper company, St. Paul, MN, USA), which was then rolled to final dimensions of $2 \mathrm{~cm}$ in diameter and $38 \mathrm{~cm}$ in height, supported vertically by a metal mesh with $2 \mathrm{~cm} \times 2 \mathrm{~cm}$ holes. The experimental design was a randomised block design with three replicate rolls per line (in 
total 12 plants per line). The bases of the rolls were placed in a tray with nutrient solution, initially containing 0.5 strength medium. After three days, nutrient solution was exchanged to $1 \times$ medium, nutrient solution was changed every day. The nutrient solution comprised: 1.5 $\mathrm{mM} \mathrm{Ca}\left(\mathrm{NO}_{3}\right)_{2}, 5 \mathrm{mM} \mathrm{KNO}_{3}, 2 \mathrm{mM} \mathrm{NaNO}_{3}, 1 \mathrm{mM} \mathrm{MgSO}_{4}, 1 \mathrm{mM} \mathrm{KH}_{2} \mathrm{PO}_{4}, 25 \mu \mathrm{M} \mathrm{FeEDTA}$, $160 \mathrm{nM} \mathrm{CuCl}_{2}, 9.2 \mu \mathrm{M} \mathrm{H}_{3} \mathrm{BO}_{3}, 3.6 \mu \mathrm{M} \mathrm{MnCl}_{2}, 16 \mathrm{nM} \mathrm{Na}_{2} \mathrm{MoO}_{4}, 5 \mu \mathrm{M} \mathrm{KCl}$, and $770 \mathrm{nM} \mathrm{ZnCl}$, at $\mathrm{pH}$ 5.8. Plants were grown in a controlled-environment growth room with $12 / 12 \mathrm{~h} \mathrm{light/dark}$ cycle, light intensity of $500 \mu \mathrm{mol} \mathrm{m} \mathrm{m}^{-2} \mathrm{~s}^{-1}, 70 \%$ relative humidity during the day and $80 \%$ during the night and temperature of $20^{\circ} \mathrm{C}$ during the day and $16{ }^{\circ} \mathrm{C}$ during the night. After 11 days (at 2-leaf stage, one unfurled), paper rolls were opened and photos were taken by camera, Image J (Schneider et al., 2012) software was used to measure root angle, then plants were taken off the germination paper and kept in $30 \%$ ethanol prior to imaging. The intact root systems were scanned as a digital image with a scanner (STD-1600, Regent Instruments, QC, Canada) and a medium image resolution of $400 \mathrm{dpi}$ was used. The root length, surface area and volume were determined from the root images using the root image analysis software WinRHIZO Pro (Regent Instruments, QC, Canada), differentiating the seminal axes and the seminal laterals with a distinguishing diameter of $0.25 \mathrm{~mm}$ (verified in each experiment). Following scanning, the plants were oven-dried at $80^{\circ} \mathrm{C}$ to determine root and shoot dry weights.

Wax layer screen

We screened 72 lines, selected from those screened with the cigar roll screen, in a wax layer experiment. The experiments were carried out in a controlled environment room with day/night temperatures of 22 and $18^{\circ} \mathrm{C}$, respectively, and a $14 \mathrm{~h}$ day length. The design of experiment is a randomised block design (72 lines $\mathrm{x}$ weak/strong wax) with two replications of the complete experiment (i.e. 72 lines $x$ weak/strong wax $x$ two replicate experiments). The relative humidity was $70 \%$ during the day and $80 \%$ at night. Lighting was by fluorescent tubes, with supplementary tungsten lighting, and the photosynthetic photon flux density was $450 \mu \mathrm{mol} \mathrm{m} \mathrm{m}^{-2} \mathrm{~s}^{-1}$ at plant height. 

previously for rice (Clark et al. 2000, 2002, 2008a, 2008b) and for wheat (Whalley et al. 2013). Wax layers were prepared by melting together mixtures of white soft paraffin (Bell, Sons \& Co. (Druggists) Ltd) and pastillated paraffin wax $\left(57-60^{\circ} \mathrm{C}\right.$ solidification point, Merck Ltd, Poole, UK) and pouring the mixture into a circular aluminium foil mould. The thickness of the wax layers was $3 \mathrm{~mm}$ and the diameter $14.4 \mathrm{~cm}$. The wax was mixed to two different concentrations; $5 \%$ of the stronger pastillated paraffin wax (weak wax layer) and $30 \%$ stronger wax (strong wax layer). The penetrometer resistances of 5 and $30 \%$ wax layers at $20^{\circ} \mathrm{C}$ are 0.024 and $0.315 \mathrm{MPa}$ respectively (Whalley et al. 2004). The cone of the penetrometer had a diameter of $2 \mathrm{~mm}$ and the cone angle was $60^{\circ}$. From previous studies (Whalley et al. 2013), these two strengths allow discrimination between lines which are good and poor at penetrating hard layers. Wax layers were installed $5 \mathrm{~cm}$ deep in sand (Redhill T grade silica sand, WBB Minerals, Sandbach, UK) in plastic growth tubes (15 cm internal diameter, $45 \mathrm{~cm}$ length), essentially as described by Whalley et al. (2013). Each tube, containing a single seedling previously germinated (on filter paper) was set up in a tank of nutrient solution with the meniscus $30 \mathrm{~cm}$ below the sand surface. The 3-4 $\mathrm{mm}$ gap between the wall of the tube and the wax layer allowed the entire core of sand to be watered by capillary action from the tank. Plants were grown for six weeks. The nutrient solution composition was $1.5 \mathrm{mM} \mathrm{Ca}\left(\mathrm{NO}_{3}\right)_{2}$, $0.15 \mathrm{mM} \mathrm{CaH}_{4}\left(\mathrm{PO}_{4}\right)_{2}, 1.0 \mathrm{mM} \mathrm{KCl}, 0.3 \mathrm{mM} \mathrm{MgSO}_{4}$, with the following micronutrients: $50 \mu \mathrm{M}$ $\mathrm{B}, 50 \mu \mathrm{M}$ Fe, $10 \mu \mathrm{M}$ Mn, $1 \mu \mathrm{M} \mathrm{Zn}, 1 \mu \mathrm{M}$ Cu and $0.5 \mu \mathrm{M}$ Mo. This nutrient solution is different to the one used in the Cigar-roll screen because we used the nutrient solutions which had been previously used separately and successfully in each screen. penetrating each wax layer were counted. The total number of roots was also counted, including those that grew down between the edge of the wax disc and the wall of the plastic growth tube. The fresh and dry weight of roots was measured for both shallower (less then $5 \mathrm{~cm})$ and deeper roots. Shoot dry weight was also measured and the number of tillers 
counted. We also measured the distance between the point of penetration on the weak wax layer and the centre of the wax disc; this was used as measure of root spread.

Field experiment

We used two experimental field sites: Warren Field (2016/2017) and the neighbouring Broadmead (2015/2016), located near Woburn, Bedfordshire, UK. The soils are described as a 'typical alluvial gley soil' with a texture classification of silty clay loam soil (similar to FAO classification Fluvisol). Both sites are managed by Rothamsted Research and have a long-history under arable agriculture using the mouldboard plough as the primary tillage. In this experiment wheats in season 2015/2016 were sown following at least one year of canola/oil seed rape (Brassica napus). The surface layer (approximately $30 \mathrm{~cm}$ ) has higher organic matter content and has a lower bulk density than deeper layers. In Warren Field wheat roots take up water to a depth of approximately $1 \mathrm{~m}$ (Shanahan et al. 2015). The soil profile on these fields is consistent with description of a soil profile by Weir et al. (1984) that should be expected to produce high yields in winter wheat.

The field sites were sown in the same manner in both years: 216 separate $9 \mathrm{~m} \times 1.8 \mathrm{~m}$ plots, divided into three fully randomised blocks, with each block containing 71 plots of different wheat lines and one fallow plot (i.e. 72 plots in total). Cultivars and fallow plots were randomly arranged within each block. The plots were sown on 13/10/2015 in 2015/16 and 28/09/2016 in 2016/17. The field sites were rain-fed with no additional irrigation. In each year, husbandry of the crops followed standard agronomic protocols for the UK, with inputs to ensure adequate nutrition, weed, pest and disease control.

Water content profiles were measured in both growth seasons. Neutron probe (CPI HydroProbe model 503TDR) readings were taken in the field. Aluminium access tubes were installed approximately $1 \mathrm{~m}$ from the end of selected plots and measurements were made at depths of $0.15,0.30,0.50,0.70,1.00,1.25$ and $1.45 \mathrm{~m}$. In 2016 , two blocks were monitored 
and in 2017 all three blocks were monitored. This was due to a more limited availability of access tubes in 2016. Soil water content profiles were measured on 16-Mar-16, 21-Apr-16, 12-May-16, 07-Jun-16, 21-Jul-16, 16-Mar-17, 05-Apr-17, 26-Apr-17, 16-May-17.

Once the wheat had come into head, $5 \mathrm{~cm}$ diameter cores were taken to a depth of 1 $\mathrm{m}$. One core was taken from each plot. Root length distributions were estimated with the core break method (White and Kirkegaard 2010; Hodgkinson et al. 2017).

Leaf area index was measured once per month with a sun-scan (Delta-T Devices, Burwell, Cambridge, UK) during the growing season. Crop height was measured with meter ruler. At harvest, grain yield was measured with a plot combine harvester.

\section{Statistical analysis}

We used using GenStat 18 (www.vsni.co.uk) for all the statistical analysis. Laboratory root data from the cigar-roll were analysed with regression. In the cigar roll screen we analysed data on root length seminal and seminal lateral roots, root growth angle and root diameter in the cigar-roll screen. In the wax-layer screen we analysed root penetration through strong and weak layers as well as the angular spread of roots was analysed with Analysis of Variance. We used a block structure of Experiment no./Pot and a treatment structure of Line*Wax layer strength. We used regression in an attempt to find correlations between data from the cigar-roll and wax-layer screens and data from the field experiment.

In the field data, the numbers of roots were transformed using square roots to stabilize the variance and the profiles modelled with linear mixed models with depth being treated as a continuous variable and line as a factor in the fixed model. The random model accounted for blocks, plots, depth (as a factor), face (the expose soil face in the core break i.e. 2) and rotation (roots were counted three times each with a rotation of $120^{\circ}$ apart from the previous count). A spline term for depth (common to all lines) was included to represent the non-linear departure from the linear response. An autoregressive term over depth was 
also included in the random model for the 2017 data to account for similarities between root lengths at adjacent depths. The model therefore included a linear trend to explain the decrease in root numbers with depth with the spline superimposed on the linear trend to account for the nonlinear nature of the root count with depth. The interaction between wheat line and depth was used to compare the slopes of the linear trend to determine if there were any significant differences between lines. (see Hodgkinson et al. 2017).

We expected that the number of shallow roots observed would limit the associated number of the deep roots because deep rooting is partly a stochastic process. From visual inspection of the data it appeared that the data did indeed conform to a boundary-line model where the boundary line describes this limit. The boundary line model, first proposed by Webb (1972), describes sets of data in which one variable (the explanatory variable) appears to limit the response of the other (the response variable). The concept is that there is some upper (or lower) limit to the value of the response variable at any given value of the independent variable so that values larger than the boundary (or smaller in the case of a lower boundary) are not possible excepting that attributed to error.

We also expected the relationship between the number of deep roots and yield to conform to a boundary-line model. Here we expected the number of deep roots to constrain the lower limit of yield. We used the method described in Lark and Milne (2016) to fit the boundary-line models. The underlying assumption to this method is that the data describe censored bivariate probability distributions. The censor in the distribution is the boundary line, and a parameter of variation quantifies the error around the boundary line. The censored bivariate distribution was fitted to the data by maximum likelihood.

\section{Results}

Cigar roll data

The distributions of root angle, root diameter, seminal lateral root length and seminal axis root length from the cigar roll screen are shown in Fig. 1. These demonstrated genotypic 
variation in the root traits (length, diameter and growth angle) of young seedlings. The

247 relationships between these different measures of root system architecture are shown in Fig.

2. Regression showed that both relationships are significant $(P<0.001)$, but only a small percentage of the variance is accounted for by regression: $10.5 \%$ for the relationship between root angle and diameter and $6.9 \%$ for the relationship between seminal lateral length and seminal axis length. Nevertheless, these data allowed us to select groups of wheat with thick steep roots, spread out fine roots, large root systems or small root systems.

Wheat group selection

We chose four groups depending on laboratory phenotype data and seed availability. The groups were as follows (Tables 1 and S1): Group 1 had thick roots with a narrow angular spread, Group 2 had thin roots with a wide angular spread, Group 4 had long seminal and seminal lateral roots, Group 5 had short seminal and seminal lateral roots, Group 3 was selected by breeders based on a priori shoot phenotypes and time to heading (plants of medium height and a mixture of early and late heading) and Group 6 was selected to make the number of lines up to 71 , this group included the dwarf and tall NILs. The reason, in part, for including of groups 3 and 6 is that they provided intermediate phenotypes that reflected the continuum of phenotypic relations described below in the 637 lines that were screened in the laboratory.

Wax layer screen

Fewer roots penetrated the strong wax layer. Of the roots that intercepted the wax layer, the mean number of penetrating roots, taken across all wheat lines, for the strong layer was 2.2 compared with 17.7 for the weak layer $(P<0.001)$. There was no genotypic effect $(P=0.384)$ nor was there any significance interaction between wax layer strength and genotype $(P=0.988)$. Some of the roots grew at a sufficiently shallow angle that they missed the wax layer and grew in the gap between the wax layer and the tube wall. These roots would not be expected to penetrate the strong wax layer (Whalley et al. 2013) and these data 
represent the total number of root axis. In these roots, there was a significant genotypic effect $(P=<0.001)$ and the data are plotted in Fig. 3. We did find that the mean number of roots penetration the hard-wax layer by group 1 was 5.33 compared to 3.65 for group 2, as might be expected (Whalley et al. 2013), however, this difference was not statistically significant. We found no correlations between root length, angle and diameter in the cigarroll screen and number of penetrating roots in the wax-layer screen.

\section{Field data}

In 2016 the mean yield was $9.2 \mathrm{t} /$ ha compared with $7.8 \mathrm{t} / \mathrm{ha}$ in 2017 . The yields for the different wheat lines are strongly correlated between the two seasons (Fig. 4). In both season, there were significant effects of wheat line on yield $(P<0.001)$. In 2016 the SED of the mean yield was 0.4962 (140 df) and in 2017 it was 0.84 (140 df). A higher mean yield in 2016 is consistent with a reduced variance and smaller SED.

The mean root depth distributions for 2016 and 2017, taken across all wheat lines, are compared in Fig. 5a. In both years, the distribution of roots deeper than approximately $35 \mathrm{~cm}$ was similar, but the number of shallow roots differed greatly. A comparison of soil drying, by taking the mean across all lines, at approximately similar soil moisture deficits (44 $\mathrm{mm}$ in 2016 and $54 \mathrm{~mm}$ in 2017) showed similar soil drying profiles (Fig. 5b). The rainfall, soil moisture deficit and temperature during both experiments are shown in Fig. 6 and the periods for the soil drying data are indicated. The greater rainfall and smaller soil moisture deficit in 2016 was consistent with the higher mean grain yield in that season.

In both seasons root distribution data for the different wheat lines were compared by fitting a spline function with an additive linear slope as described by Hodgkinson et al. (2017). The slopes of the linear trend between root count and depth were significantly affected by wheat line in $2016(P=0.002)$ and $2017(P=0.001)$. Although in each year there was a significant line effect, there was no correlation between the slopes of the linear trend 
between years, indicating that the wheat lines behaved differently in each year. In Fig. 7 the number of deep roots is plotted against the number of shallow roots. The fitted boundary line indicates that when a wheat had many shallow roots, it was more likely to have deep roots. The scatter around the boundary was relatively sparse and so its exact position is uncertain as indicated by the error (see Table 2).

We did not find a tight correlation between grain yield and deep root count. The relationship between the number of deep roots and yield could be described by a boundary line model (Fig. 8), however, which showed that if a wheat did have deep roots it was unlikely to have a low grain yield (see Table 2). Regression between yield and the number of shallow or deep roots are summarised in Table 3. In the drier of the two seasons (2017 see Fig. 6) the deep roots were more important and accounted for $13 \%$ of the variance in yield compared with $4 \%$ in 2016 . In both years an increasing number of shallow roots was associated with a higher yield (Table 3). At some depths it was possible to obtain correlations between root count and soil drying, but they were too weak to give similar a ranking of wheat line between soil drying and root count.

The mean leaf area index data are plotted in Fig. S1. These data and soil drying data, along with root diameter data allowed empirical relationships to be developed which could explain as much as $57 \%$ of the grain yield. However, this empirical correlation depended on the season and it is unlikely to be replicated in different years; the effects of "soil drying" and "year" on yield had a significant interaction at $\mathrm{P}=0.011$.

Relationships between laboratory screens and field experiments

We were unable to find any relationships between the laboratory root screens and root growth in the field. We did find that, using grouped regression, grain yield was positively correlated with root diameter and explained 44.6 percent of the variance in grain yield $(P<0.001)$ (Fig 9). This relationship is also seen in Table 4, where Group 2, which contained narrow roots, has a lower yield in both seasons. A correlation matrix for both years to 
compare data from the cigar-roll screen, wax-layer screen and field experiment is shown in Table 5.

\section{Discussion}

In each year, there was genotypic variation in root depth in the field, however, we did not find any consistency between the two seasons. The ranking of yield was very consistent between the two seasons, indicating plant plasticity in conserving yield. We did find some consistency in the comparison of two Rht NILs. Here an extreme dwarf had deeper roots in both seasons in comparison with a tall wheat. Hodgkinson et al. (2017) also found that the same dwarf NIL had deeper roots than the tall NIL in one out of two years, while in the second-year rooting depths were similar, which was attributed to higher levels of soil moisture during early growth. In common with Hodgkinson et al. (2017), we found that wheat had a much greater number of shallow roots on Warren Field in comparison with Broadmead. Wasson et al. (2014) also found that different fields gave consistently different root length distributions with depth across a number of different wheat genotypes. That the field appears to have a consistent effect on the distribution of roots with depth, highlights the effect of soil on root length distribution with depth. However, it is not clear which aspects of the soil profile in Warren Field encourage a greater number of shallow roots compared with Broadmead. In this work, we found the distributions of deep roots were similar in both season (Fig. 5). Boundary line analysis showed that deep roots are more likely, if there are a large number of shallow roots (Fig. 7). However, it should be noted that the large difference in the number of shallow roots between seasons did not appear to greatly affect the distribution of deep roots (Fig. 5). Although, the number of deep roots in Broadmead was slightly smaller.

Roots with larger diameters are better at penetrating hard layers in laboratory studies; this has been found for rice (Clark et al. 2002) and maize (Chimungu et al. 2015). In rice and maize there is a much greater diversity in diameter compared with wheat where the 
range of diameters is small (Fig. 1). In maize, there was a twofold difference between the smallest and greatest diameter maize (Chimungu et al. 2015) whereas in rice there was an 8-fold increase in diameter between rice lines with the smallest root diameters and those with the greatest (Clark et al. 2008). In wheat, not only are root diameters are much smaller, with a mean diameter of approximately $0.5 \mathrm{~mm}$ compared to about $1.5 \mathrm{~mm}$ for maize and 1.2 $\mathrm{mm}$ for rice, but the range in root diameters is also small. Root angle is a trait that is also associated with deep roots (Lynch et al. 2014). Steep roots increase the probability that roots will successfully penetrate a hard layer (Whalley et al. 2013) although root angle may also have some effect on how root system architecture interacts with soil structure. Plants with a narrower angular spread of roots are thought to be at an advantage in water-limited environments (Manschadi et al., 2006, 2008), whereas a wide angular spread of roots is thought to benefit nutrient uptake, especially P (Ge et al., 2000; Rubio et al., 2001; Lynch, 2007, 2011; Shen et al., 2013). We measured root angle at the seedling stage, as is commonplace in high-throughput root screens, but found no correlation with root depth in the field. In this project, we deliberately grew lines in the field with contrasting laboratory rootphenotypes. None of the data from laboratory root screens (cigar roll or wax layer) were correlated with any aspect of root growth in the field. Watt et al. (2013) also found no relationship between data from seedling root screens and the rooting patterns of mature wheat in the field, although there was evidence that laboratory screens could predict root depth in the field at the five-leaf stage $(P=0.02)$.

Root diameter from our high throughput laboratory screen was correlated with grain yield. We have no evidence to support the idea that this was in any way related to improved root growth. We found no correlation between root diameter and water uptake or root depth. Gong and Macdonald (2017) found that two QTLs for root diameter were associated with major QTLs for grain yield in barley. Given that neither improved water uptake nor root depth appeared to be related to root diameter it is most likely that the eff ect of root diameter on yield is related to some unknown pleiotropic effect. Atkinson et al. (2015) found two QTLs for 
seedling root traits that co-localized with QTLs quantified from field trials for grain yield and $\mathrm{N}$ uptake, on chromosomes $2 \mathrm{~B}$ and $7 \mathrm{D}$, respectively. Although the seedling traits did not include root diameter. Thomas et al. (2016) found that, in oil seed rape, seed yield was correlated with the length of primary roots in high throughput screens similar to the one we used in this work. However, for wheat we found no such relationships.

Boundary line analysis showed that wheat lines with deep roots are not likely to have low yields, although, deep roots, at least in the UK, are not an essential trait for high yielding commercial wheat varieties. In the drier of the two years, 2017 , the number of deep roots (45 to $95 \mathrm{~cm}$ ) was positively correlated with higher yields (Table 3). Unfortunately, the simple laboratory-based root screens do not seem to be able to predict root depth. Furthermore, root depth does not seem to be a trait that can be observed consistently between seasons in any given wheat line. An exception to this is the comparison between the dwarf and tall NILs, where the dwarf NIL gave consistently deeper rooting. This may be due to greater number of roots in the dwarf NIL compared with the tall NIL.

\section{Conclusion}

Wheat lines with deep roots are high yielding, but it is not essential to have deep roots for high yields in the UK environment. The deepest rooting wheat lines were amongst those with the greatest number of shallow roots. This implies a stochastic element in determining rooting depth. We did not find, in our field experiments for wheat, a simple laboratory screening method that produced a phenotype that was correlated with rooting depth of mature plants in the field. We did find that root diameter measured in high throughput screens was correlated with yield, for reasons that remain to be determined. While the yield of 71 wheat lines was highly correlated over two seasons, we found little consistency in root growth. In dryer years, we have confirmed that wheat lines with deep rooting are associated with increased yields.

\section{Acknowledgments}


404 The work described in the paper was funded by Syngenta Ltd. 


\section{References}

Atkinson JA, Wingen LU, Griffiths M, Pound MP, Gaju O, Foulkes MJ, Gouis JL, Griffiths S, Bennett MJ, King J, Wells DM (2015) Phenotyping pipeline reveals major seedling root growth QTL in hexaploid wheat. Journal of Experimental Botany 66:2283-2292

Bai C, Liang Y, Hawkesford MJ (2013) Identification of QTL associated with seedling root traits and their correlation with mature plant height in wheat. J Exp Bot 64, 1745-53.

Barraclough, P.B., Leigh, R., 1984. The growth and activity of winter wheat roots in the field: the effect of sowing date and soil type on root growth of high yielding crops. J Agr Sci 130, 59-74.

Clark LJ, Aphalé SL, Barraclough PB (2000) Screening the ability of rice roots to overcome the mechanical impedance of wax layers: importance of test conditions and measurement criteria. Plant Soil 219:187-196

Clark LJ, Cope RE, Whalley WR, Barraclough, P.B. and Wade, L.J. (2002) Root penetration of strong soil in rainfed lowland rice: comparison of laboratory screens with field performance. Field Crop Res 76:189-198.

Clark LJ, Ferraris S, Price AH, Whalley WR (2008a) A gradual rather than abrupt increase in strength gives better root penetration of strong layers. Plant Soil. 307: 235-242.

Clark LJ, Price AH, Steele KA, Whalley WR (2008b) Evidence from near-isogenic lines that root penetration increases with root diameter and bending stiffness in rice. Funct Plant Biol 35: 1163-1171

Chimungu JG, Loades KW, Lynch JP (2015) Root anatomical phenes predict root penetration ability and biomechanical properties in maize (Zea Mays). J Exp Bot 66, 3151-3162.

Fan J, McConkey B, Wang H, Janzen H (2016) Root distribution for temperate agricultural crops. Field Crop Res 189, 68-74.

Gao W, Hodgkinson L, Jin K, Watts CW, Ashton RW, Shen J, Ren T, Dodd IC, Binley A, Phillips AL, Hedden P, Hawkesford MJ, Whalley WR (2016) Deep roots and soil structure. Plant Cell Environ 39, 1662-1668.

Ge ZY, Rubio G, Lynch JP (2000) The importance of root gravitropism for inter-root competition and phosphorus acquisition efficiency: results from a geometric simulation model. Plant Soil 218, 159-171

Gerwitz A, Page ER (1974) An empirical mathematical model to describe plant root systems. J Applied Ecol 11, 773-781.

Gregory PJ, McGowan M, Biscoe PV, Hunter B (1978a) Water relations in winter wheat 1. Growth of the root system. J Agric Sci 91, 91-102

Gregory, PJ, McGowan M., Hunter B, 1978b. Water relations in winter wheat 2. Soil water relations J Agric Sci 91,103-116

Hodgkinson L, Dodd IC, Binley A, Ashton RW, White RP, Watts CW, Whalley WR (2017) Root growth in field-grown winter wheat: some effects of soil conditions, season and genotype. Eur J Agron 91, 74-83

Jin K, Shen JB, Ashton R, White RP, Dodd IC, Parry MAJ, Whalley WR (2015) Wheat root growth responses to horizontal stratification of fertiliser in a water-limited environment. Plant Soil 386, 77-88.

Kalogoris DI, Adi MO, White PJ, Broadley MR, Draye X, Ptashnyk M, Bengough AG, Dupuy LX (2017) Analysis of Root growth from a phenotypying data set using a density-based model J Exp Bot 67: 1045-1058.

Kenobi K, Atkinson JA, Wells DM, Gaju O, De Silva JG, Foulkes MJ, Dryden IL, Wood ATA, Bennett MJ (2017) J Exp Bot 68: 4969-4981

Lark RM, Milne AE (2016) Boundary line analysis of the effect of water-filled pore space on nitrous oxide emission from cores of arable soil. Eur J Soil Sci 67 (2). 148-159. 10.1111/ejss. 12318

Lupton FGH, Oliver RH, Ellis FB, Barnes BT, Howse KR, Welbank PJ, Taylor PJ (1974) Root and shoot growth of semi-dwarf and taller wheats. Annals Appl Biol 77,129-144.

Lynch JP (2007) Roots of the second green revolution. Aust J Bot 55, 493-512. 
Lynch JP (2011) Root phenes for enhanced soil exploration and phosphorus acquisition: tools for future crops. Plant Physiol 156, 1041-1049.

Lynch JP, Chimungu JG, Brown KM (2014) Root anatomical phenes associated with water acquisition from drying soil: targets for crop improvement. J Exp Bot 65, 6155-6166.

Manschadi A, Hammer GL, Christopher J, DeVoil P (2008) Genotypic variation in seedling root architectural traits and implications for drought adaptation in wheat (Triticum aestivum L.). Plant Soil 303, 115-129

Ober ES, Werner P, Flatman E, Angus WJ, Jack P, Smith-Reeve L, Tapsell C (2014) Genotypic differences in deep water extraction associated with drought tolerance. Functional Plant Biol 41, 1078-1086.

Rubio V, Linhares F, Solano R, Martin AC, Iglesias J, Leyva A, Paz-Ares J (2001) A conserved MYB transcription factor involved in phosphate starvation signaling both in vascular plants and in unicellular algae. Gene Dev 15, 2122-2133.

Schneider CA, Rasband WS, Eliceiri KW (2012) NIH Image to ImageJ: 25 years of Image Analysis. Nat Methods 9(7), 671-675

Shanahan P, Binley A, Whalley WR, Watts CW (2015) The use of electromagnetic induction (EMI) to monitor changes in soil moisture profiles beneath different wheat cultivars. Soil Sci Soc Am J 79:459-466

Shen JB, Li CJ, Mi GH, Li L, Yuan LX, Jiang RF, Zhang FS (2013) Maximizing $\mathrm{root} /$ rhizosphere efficiency to improve crop productivity and nutrient use efficiency in intensive agriculture of China. J Exp Bot 64, 1181-1192.

Steele KA, Price AH, Witcombe J, Shrestha BN, Singh BN, Gibbons JM, Virk DS (2013) QTLs associated with root traits increase yield in upland rice when transferred through marker-assisted selection. Theor Appl Genet 126: 101-108.

Thomas CL, Graham NS, Hayden R, Meacham MC, Neugebauer K, Nightingale M, Dupuy L, Hammond JP, White PJ, Broadley MR (2016) High-throughput phenotyping (HTP) identifies seedling root traits linked to variation in seed yield and nutrient capture in fieldgrown oilseed rape (Brassica napus L.). Ann Bot 118, 655-665

Watt M, Moosavi S, Cunningham SC, Kirkegaard JA, Rebetzke GJ, Richards RA (2013) A rapid,controlled- environment seedling root screen for wheat correlates well with rooting depths at vegetative, but not reproductive, stages at two field sites. Ann Bot 112: 447455, 2013.

Wasson AP, Rebetzke GJ, Kirkegaard JA, Christopher J, Richards RA, Watt M (2014) Soil coring at multiple field environments can directly quantify variation in deep root traits to select wheat genotypes for breeding. J Exp Bot 54, 6231-6249.

Webb (1972) Use of the Boundary Line in the analysis of biological data. J. Horticultural Science 47, $309-319$.

Weir AH, Rayner JH, Catt JA, Shipley DG, Hollies JD (1984) Soil factors affecting the yield of winter wheat, analysis of results from I.C.I. surveys 1979-80. J Agric Sci Camb 103, 639-649

Whalley WR, Binley A, Watts CW, Shanahan P, Dodd IC, Ober ES, Ashton RW, Webster CP, White RP, Hawkesford MJ (2017) Methods to estimate changes in soil water for phenotyping root activity in the field. Plant Soil 415, 407-422.

Whalley WR, Clark LJ, Finch-Savage WE, Cope RE (2004) The impact of mechanical impedance on the emergence of carrot and onion seedlings. Plant Soil 265: 315-323.

Whalley WR, Dodd IC, Watts CW, Webster CP, Phillips AL, Andralojc J, White RP, Davies, WJ, Parry, MAJ (2013) Genotypic variation in the ability of wheat roots to penetrate wax layers. Plant Soil 364, 171-179.

White R, Kirkegaard JA, (2010) The distribution and abundance of wheat roots in a dense, structured subsoil - implications for water uptake. Plant Cell Environ 33, 133-148.

White CA, Sylvester-Bradley R, Berry PM (2015) Root length densities of UK wheat and oilseed rape crops with implication for water capture and yield. J Exp Bot doi,10.1093/jxb/erv077 
Zhu J, Kaeppler SM, Lynch JP (2005) Mapping of QTLs for lateral root branching and length in maize (Zea mays L.) under differential phosphorus supply. Theor Appl Genet 111, 688695. 


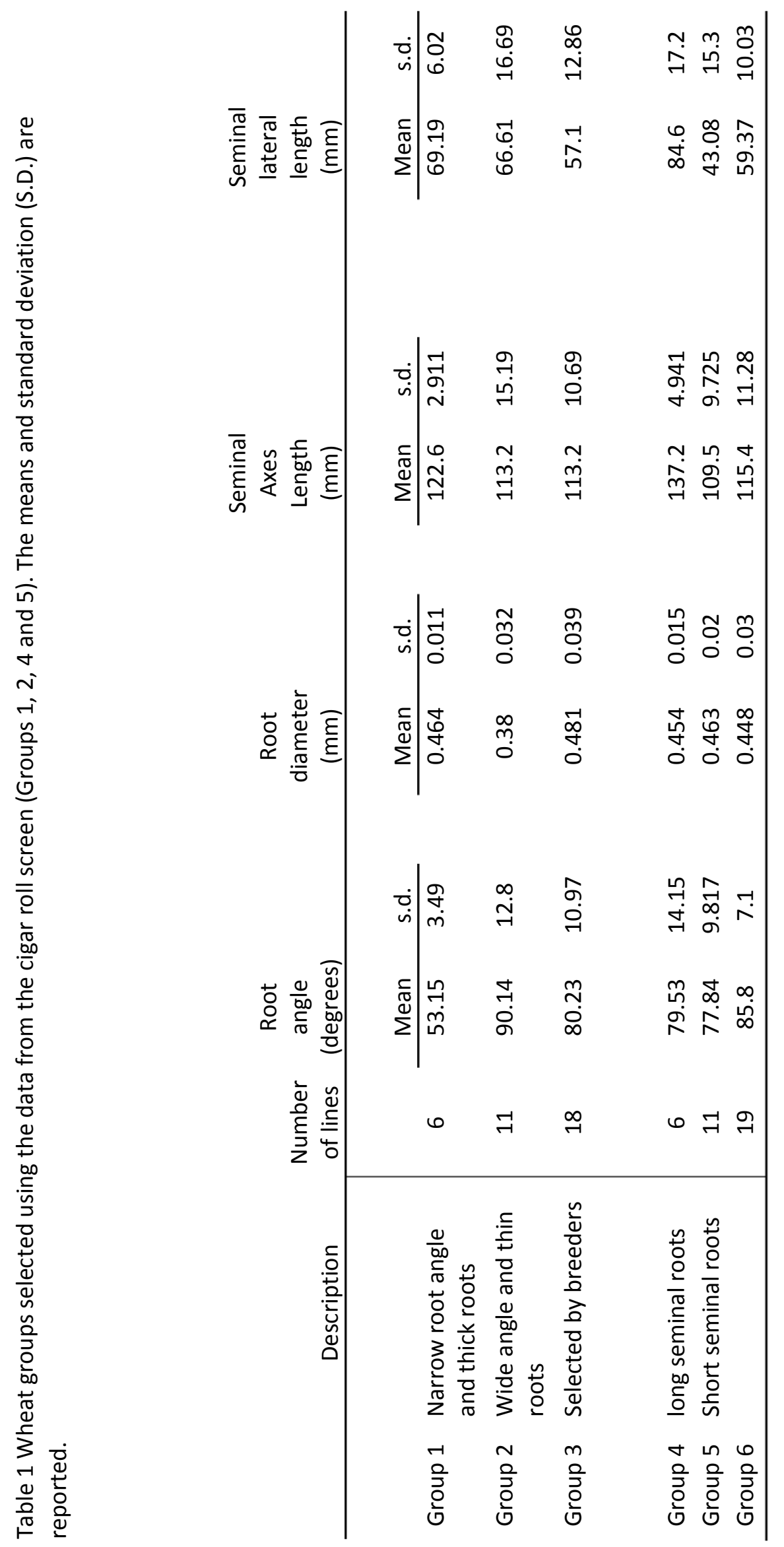


Table 2. Estimated parameter values for the fitted boundary-line models $(y=a x+b)$ and estimated error around the boundary

\begin{tabular}{l|ccc}
\hline & $\begin{array}{c}\text { Parameter } a \text { with 95\% } \\
\text { confidence interval }\end{array}$ & $\begin{array}{c}\text { Parameter } b \text { with 95\% } \\
\text { confidence interval }\end{array}$ & $\begin{array}{c}\text { Error with 95\% } \\
\text { confidence interval }\end{array}$ \\
\hline $\begin{array}{l}\text { Deep vs shallow } \\
\text { root length 2016 }\end{array}$ & $0.67(0.42,0.91)$ & $-17.10(-27.34,-6.87)$ & $2.67(1.89,4.15)$ \\
$\begin{array}{l}\text { Deep vs shallow } \\
\text { root length 2017 }\end{array}$ & $0.55(0.16,0.94)$ & $-23.74(-46.31,-1.16)$ & $5.90(0.79,11.02)$ \\
$\begin{array}{l}\text { Yield vs deep } \\
\text { root length 2016 }\end{array}$ & $0.41(0.30,0.52)$ & $-0.08(-1.96,2.11)$ & $0.53(0.16,0.90)$ \\
$\begin{array}{l}\text { Yield vs deep } \\
\text { root length 2017 }\end{array}$ & $0.29(0.16,0.42)$ & $1.27(-1.45,3.98)$ & $1.09(0.24,1.95)$ \\
\hline
\end{tabular}

Table 3 Linear correlations between yield and either the count of shallow or deep roots $(R)$.

Yield, $Y$, is regressed against the total count of roots in the shallow or deep layers

\begin{tabular}{l|cc}
\hline $\begin{array}{l}\text { Shallow or deep } \\
\text { rooting }\end{array}$ & 2016 & 2017 \\
\hline $\begin{array}{l}\text { Total root count } \\
5 \text { to } 35 \mathrm{~cm}\end{array}$ & $Y=0.066 R+5.245$ & $Y=0.040 R+4.35$ \\
& $\begin{array}{c}\text { Accounts for } 18 \% \text { of the variance } \\
\mathrm{P}<0.001\end{array}$ & $\begin{array}{c}\text { Accounts for } 13 \% \text { of the variance } \\
\mathrm{P}<0.001\end{array}$ \\
$\begin{array}{l}\text { Total root count } \\
45 \text { to } 95 \mathrm{~cm}\end{array}$ & $Y=0.076 R+8.131$ & $Y=0.099 R+6.76$ \\
& $\begin{array}{c}\text { Accounts for } 4 \% \text { of the variance } \\
\mathrm{P}=0.045\end{array}$ & $\begin{array}{c}\text { Accounts for } 13 \% \text { of the variance } \\
\mathrm{P}<0.001\end{array}$ \\
$\begin{array}{l}\text { Accumulated } \\
\text { soil moisture } \\
\text { deficit }\end{array}$ & $-12829 \mathrm{~mm}$ days & $-22761.8 \mathrm{~mm}$ days \\
\end{tabular}




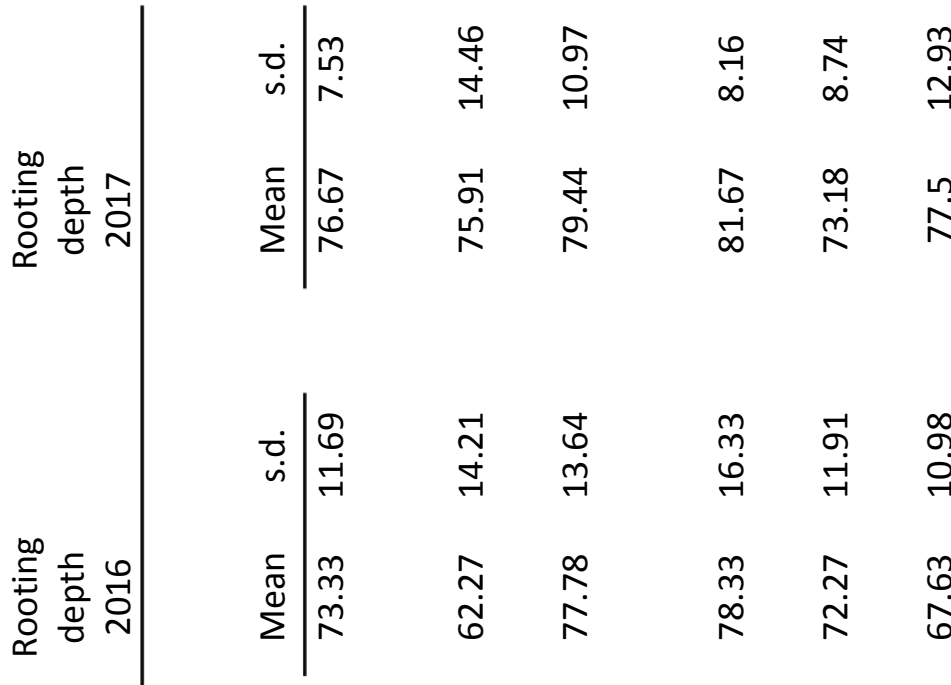

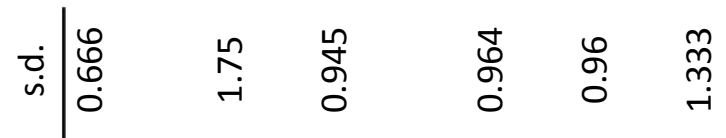

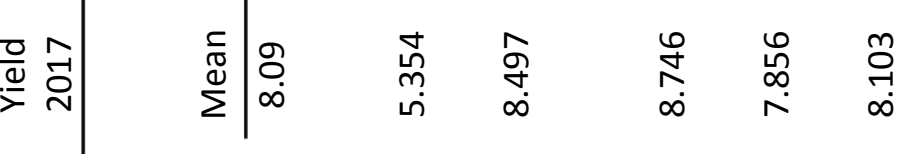

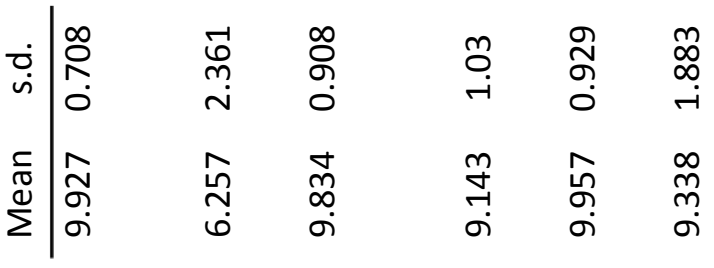
$\begin{array}{ll}0 & 0 \\ \frac{0}{0} & 0 \\ & 0\end{array}$

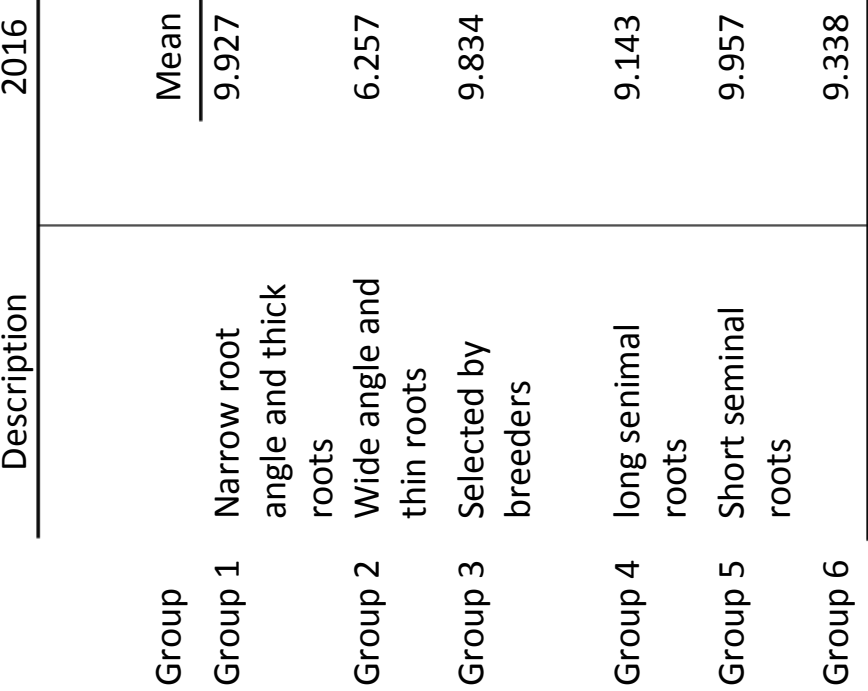


Table 5. A correlation matrix for both years to compare data from the cigar-roll screen, waxlayer screen and field experiment. Those correlations that correspond to a significant regression are shown in bold and highlighted in grey.

\begin{tabular}{|c|c|c|c|c|c|c|c|c|c|}
\hline \multicolumn{10}{|c|}{2016} \\
\hline \multirow[b]{2}{*}{ 证 $\frac{\pi}{\frac{\pi}{\pi}}$} & Grain yield & - & & & & & & & \\
\hline & $\begin{array}{l}\text { Depth of deepest root } \\
\text { in the field } \\
\end{array}$ & 0.1777 & - & & & & & & \\
\hline \multirow{4}{*}{ 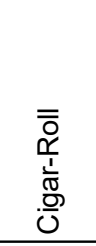 } & Root Angle & -0.072 & -0.1817 & - & & & & & \\
\hline & \begin{tabular}{|l|}
$\begin{array}{l}\text { Seminal Axes Average } \\
\text { Diameter }\end{array}$ \\
\end{tabular} & 0.58 & 0.104 & -0.2969 & - & & & & \\
\hline & Seminal Axes Length & 0.0516 & -0.1505 & -0.1779 & 0.1722 & - & & & \\
\hline & Seminal Lateral length & -0.179 & -0.0527 & -0.0672 & -0.1948 & 0.5632 & & & \\
\hline \multirow{2}{*}{ 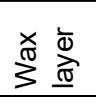 } & Number of Roots & -0.0082 & -0.1178 & -0.0386 & -0.0191 & 0.2639 & 0.1032 & - & \\
\hline & Hard Layer Penetration & -0.0423 & 0.0117 & -0.2133 & -0.051 & 0.1468 & 0.157 & 0.0698 & - \\
\hline & $\begin{array}{l}\frac{0}{0} \\
\frac{0}{\lambda} \\
. \frac{C}{\sqrt{0}} \\
\frac{10}{0}\end{array}$ & 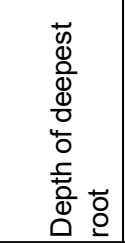 & 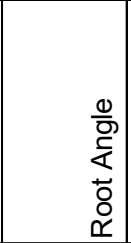 & 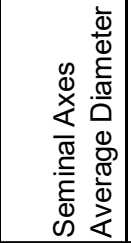 & 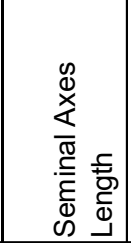 & 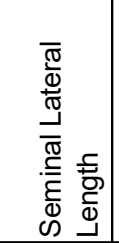 & 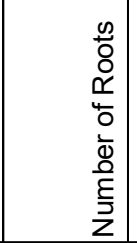 & 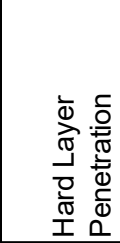 \\
\hline & & \multicolumn{2}{|c|}{ Field data } & \multicolumn{4}{|c|}{ Cigar-Roll } & \multicolumn{2}{|c|}{ Wax layer } \\
\hline \multicolumn{10}{|c|}{2017} \\
\hline \multirow[b]{2}{*}{$\frac{0}{0} \frac{\pi}{2} \frac{\pi}{\pi}$} & Grain yield & - & & & & & & & \\
\hline & $\begin{array}{l}\text { Depth of deepest root } \\
\text { in the field }\end{array}$ & 0.1974 & - & & & & & & \\
\hline \multirow{4}{*}{$\begin{array}{l}\overline{\overline{0}} \\
\frac{\alpha}{1} \\
\frac{1}{\bar{\sigma}} \\
\frac{0}{0}\end{array}$} & Root Angle & -0.0616 & 0.0706 & - & & & & & \\
\hline & \begin{tabular}{|l|} 
Seminal Axes Average \\
Diameter
\end{tabular} & 0.6239 & -0.0045 & -0.2901 & - & & & & \\
\hline & Seminal Axes Length & 0.2343 & 0.2282 & -0.1647 & 0.1487 & - & & & \\
\hline & Seminal Lateral length & -0.0483 & 0.1166 & -0.057 & -0.2159 & 0.5516 & & & \\
\hline \multirow{2}{*}{ 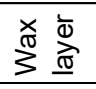 } & Number of Roots & -0.0203 & 0.1824 & -0.0316 & -0.0311 & 0.2507 & 0.0919 & - & \\
\hline & Hard Layer Penetration & -0.0038 & -0.0956 & -0.2084 & -0.0616 & 0.1328 & 0.1481 & 0.0631 & - \\
\hline & & $\begin{array}{l}\frac{0}{0} \\
\frac{0}{\lambda} \\
. \frac{C}{\pi} \\
\frac{\pi}{0} \\
0\end{array}$ & 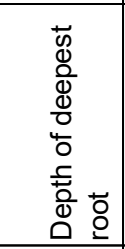 & 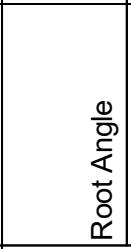 & 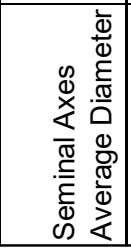 & 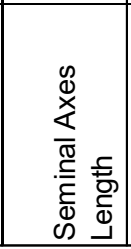 & 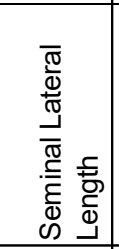 & 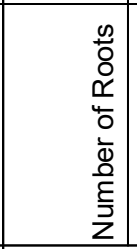 & 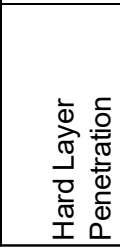 \\
\hline & & \multicolumn{2}{|c|}{ Field data } & \multicolumn{4}{|c|}{ Cigar-Roll } & \multicolumn{2}{|c|}{ Wax layer } \\
\hline
\end{tabular}


Captions

Fig. 1 Distributions of root angle (degrees), root diameter $(\mathrm{mm})$, seminal lateral root length $(\mathrm{mm})$ and seminal axis root length $(\mathrm{mm})$ in the data from the cigar-roll screen of 637 wheat lines, shown as histograms.

Fig. 2 The relationship between root growth angel and root diameter and between the lengths of the seminal axes and the seminal lateral roots for the wheat lines screened with the Cigar roll method. Linear regression showed that both relationships are significant $(P<0.001)$, but only a small percentage of the variance is accounted for by regression: $10.5 \%$ for the relationship between root angle and diameter and $6.9 \%$ for the relationship between seminal lateral length and seminal axis length.

Fig. 3. The main effect of root number penetrating the wax layer. The interaction between wheat line and the strength of the wax layer was not significant $(P=0.117)$; the data plotted are the means taken across both wax layer treatments. The SED from ANOVA is plotted.

Fig. 4. Grain yield from 71 wheat lines from two successive seasons plotted against each other. Although, the mean yields were different in each season, these data demonatrte that the ranking of the wheat lines according to grains yield was similar in both seasons.

Fig. 5 Mean root distributions with depth and the mean change in water content. Comparisons of soil drying are made at similar soil water deficits (44 mm on 12 May 2016 and $54 \mathrm{~mm}$ on 26 April 2017) and the standard error of the means are shown.

Fig. 6 Rainfall $(\mathrm{mm})$ and potential soil moisture deficit data $(\mathrm{mm}$, calculated with the Penman-Monteith method). The sowing and harvest dates are also indicated.

Fig. 7 The deep root count plotted against the shallow root count. The solid line is the fitted boundary lines showing that deep rooting is more likely if there are large numbers of shallow roots. The deep root count is the sum of all root counts between 45 and $95 \mathrm{~cm}$ and the shallow root count is the sum of all root counts between 0 and $35 \mathrm{~cm}$.

Fig. 8. Grain yield plotted against deep root count (sum of all root counts between 45 and 95 $\mathrm{cm}$ ). The solid lines are the fitted boundary lines showing that wheat with deep roots is likely to be high yielding, but deep roots, in UK conditions, are not essential for high yields.

Fig. 9 The relationship between grain yield in the field experiment and root diameter in the cigar-roll screen. A regression line fitted to all data for both seasons accounted for 30.9 percent of the variance in yield $(P<0.001)$. Grouped regression with separate fitted curves 
for each season (shown in the figure) accounted for 43.2 percent of the variance in yield $(P<0.001)$. 

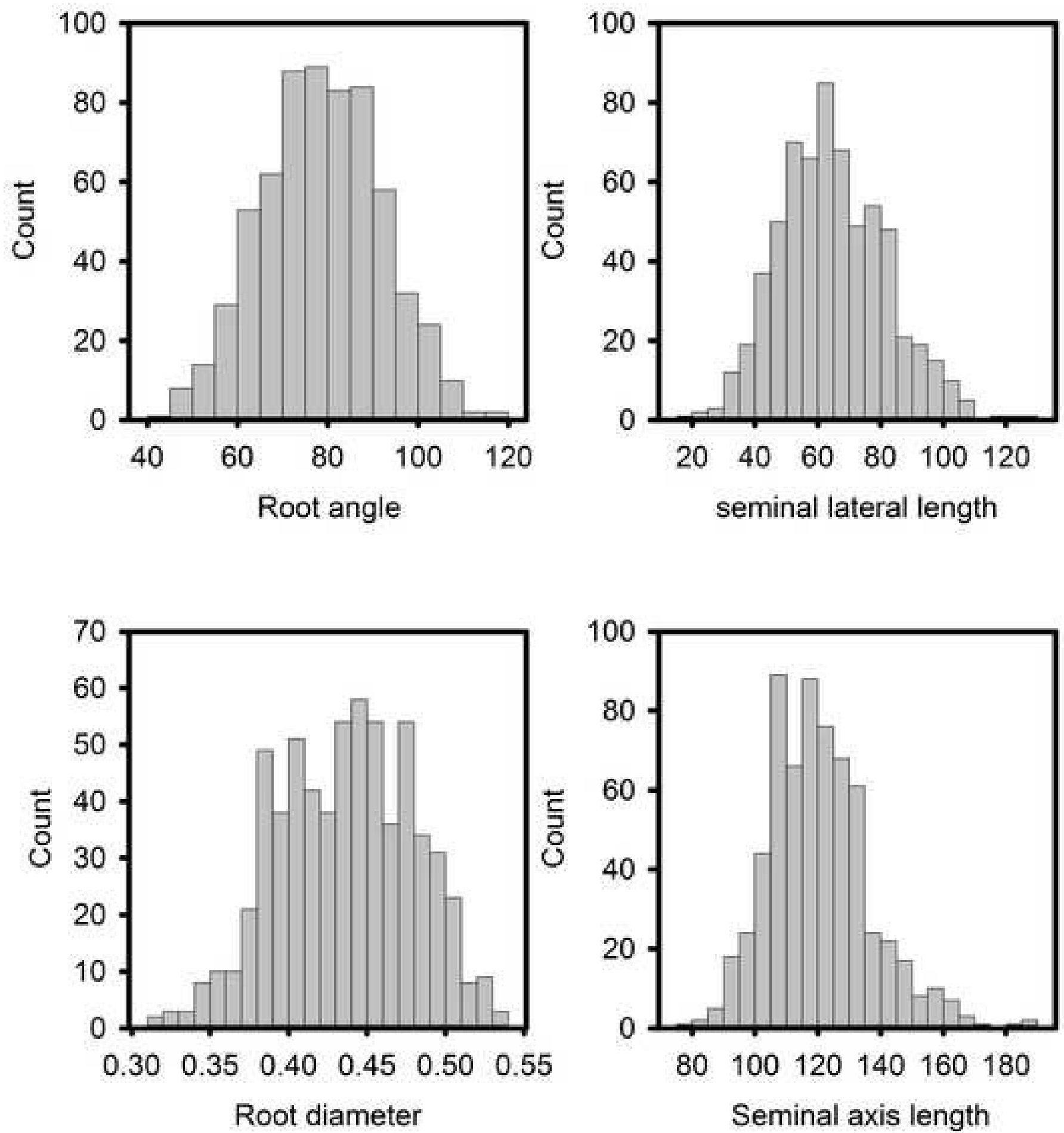

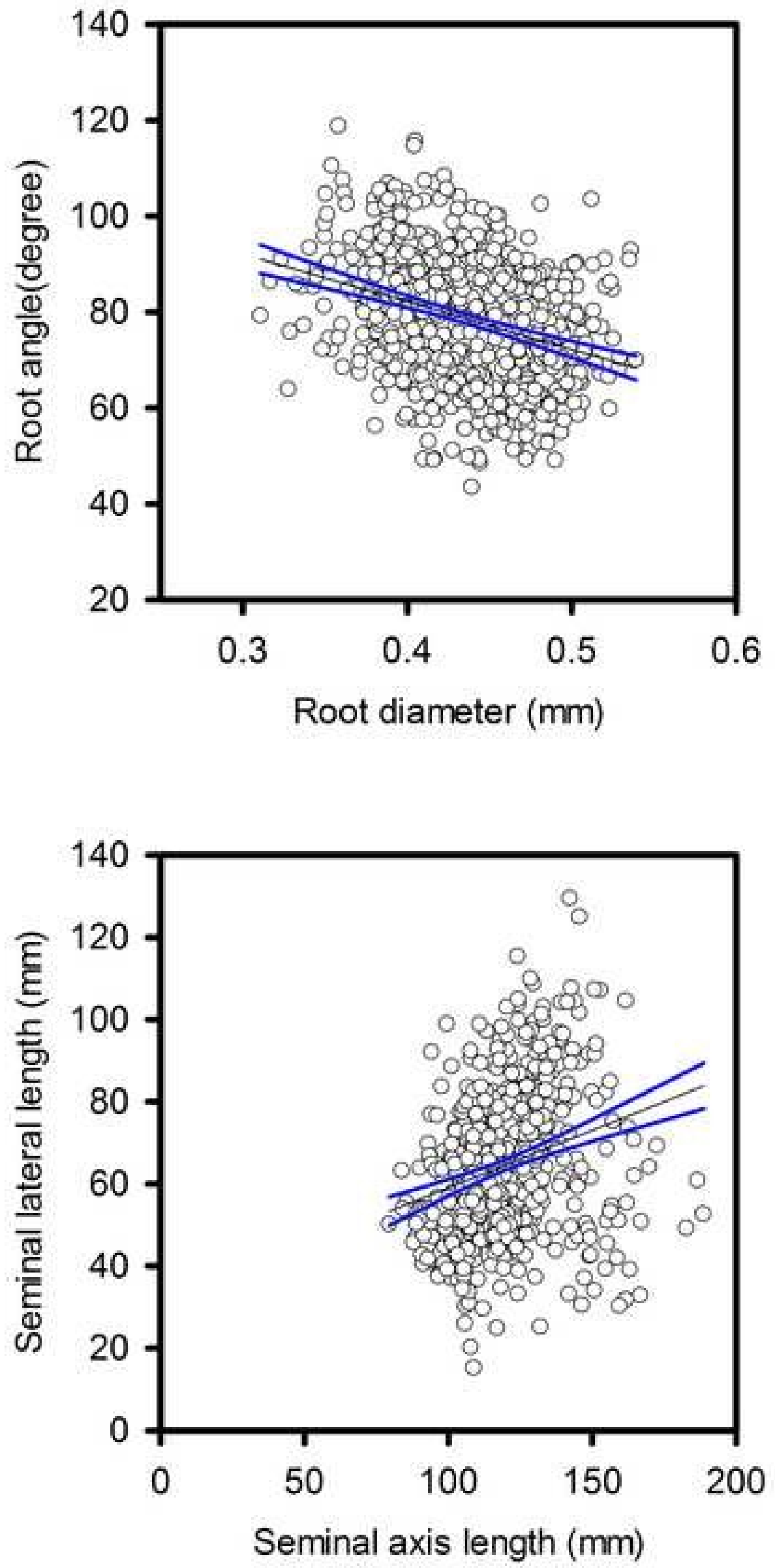


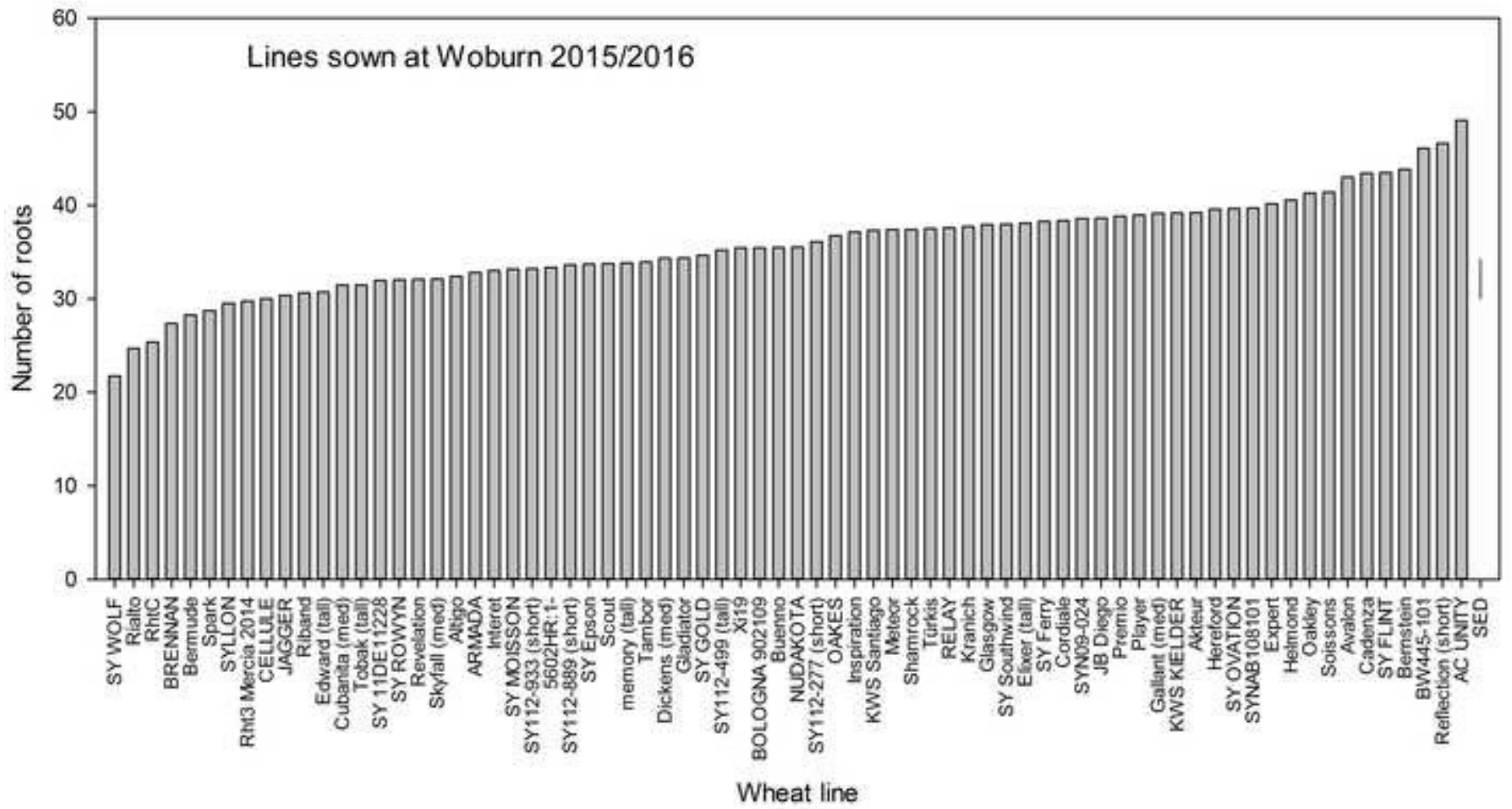




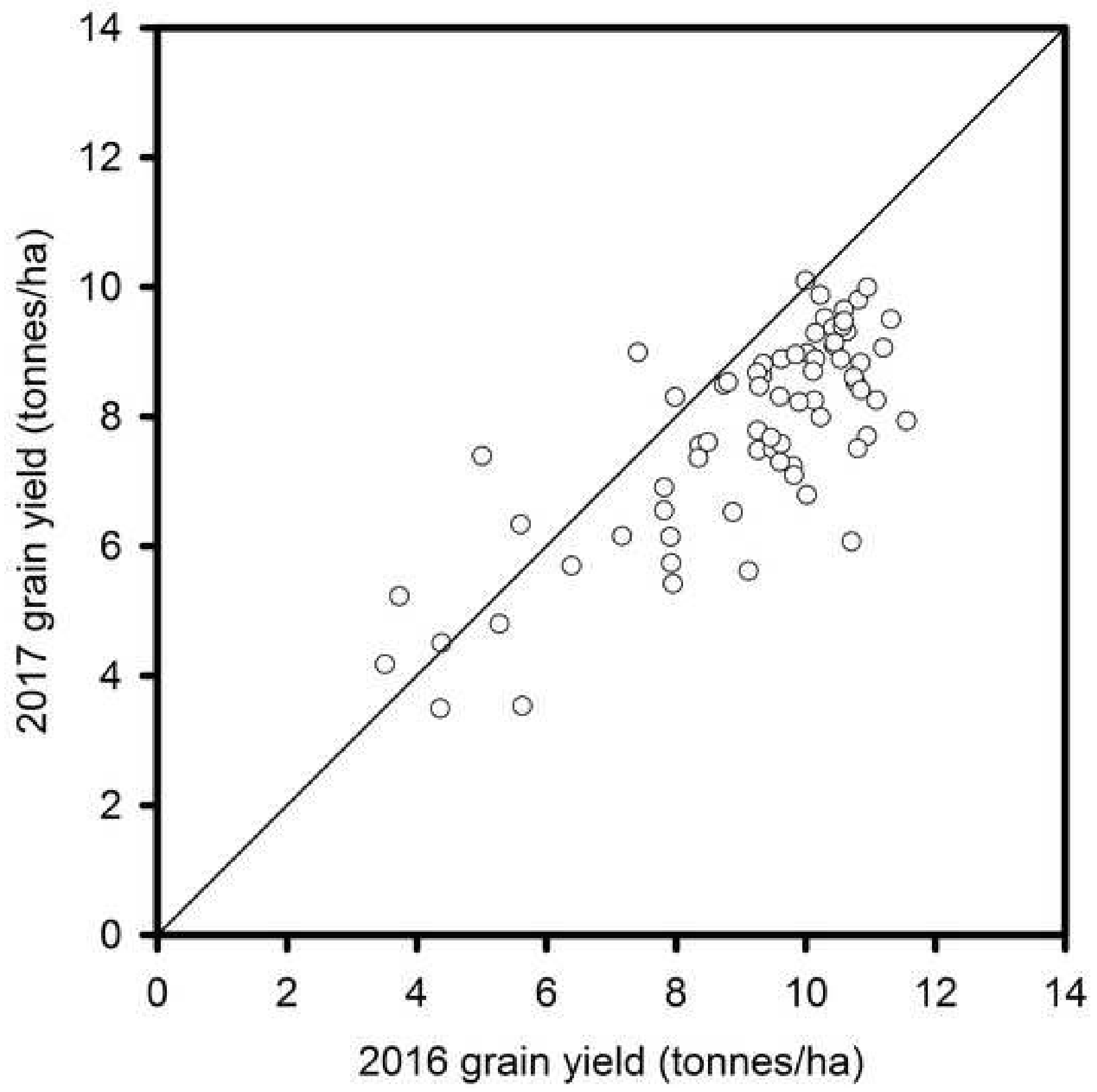



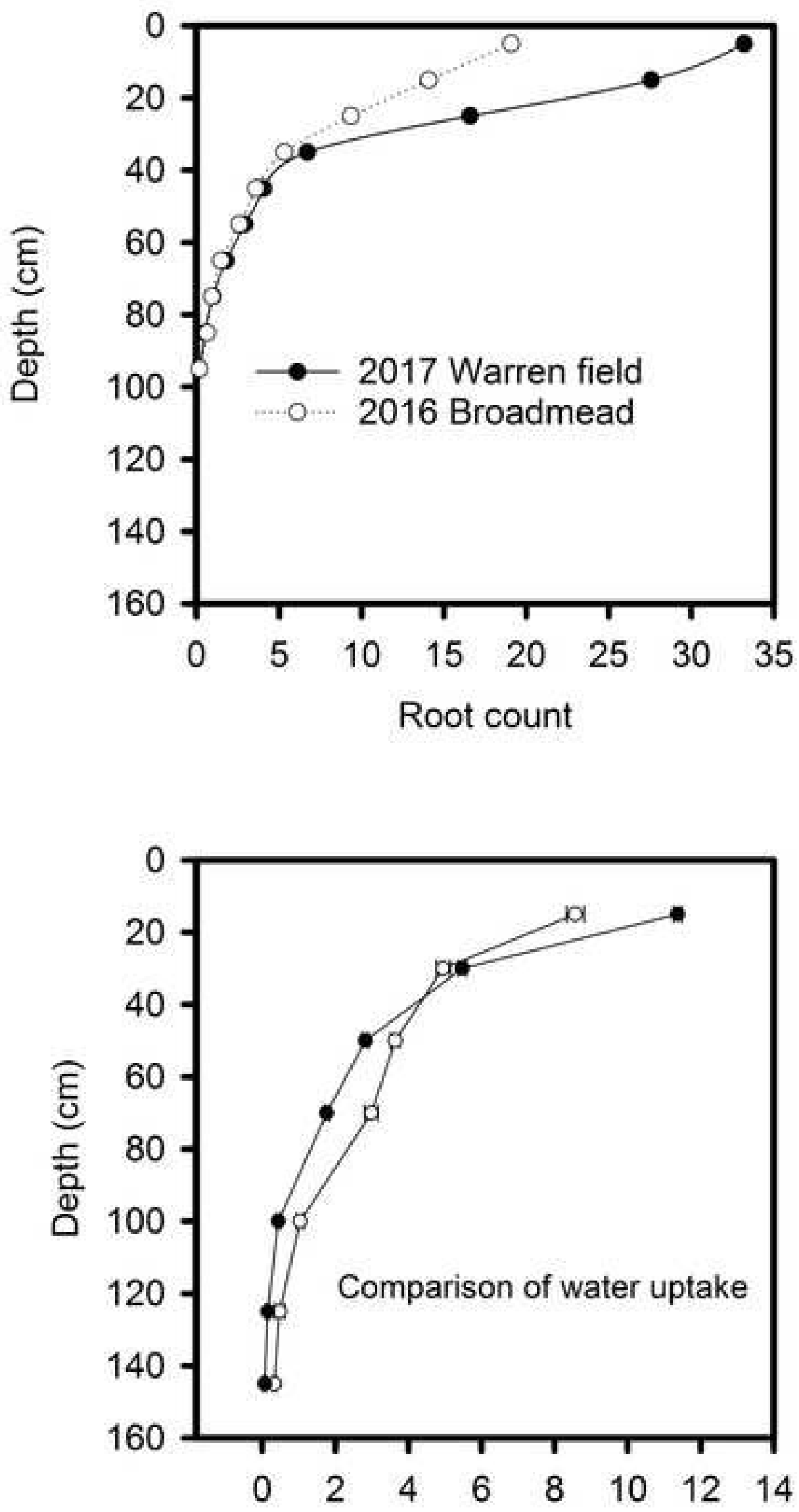

Change in water content $\left(\mathrm{cm} / \mathrm{cm}^{3}\right)$ 


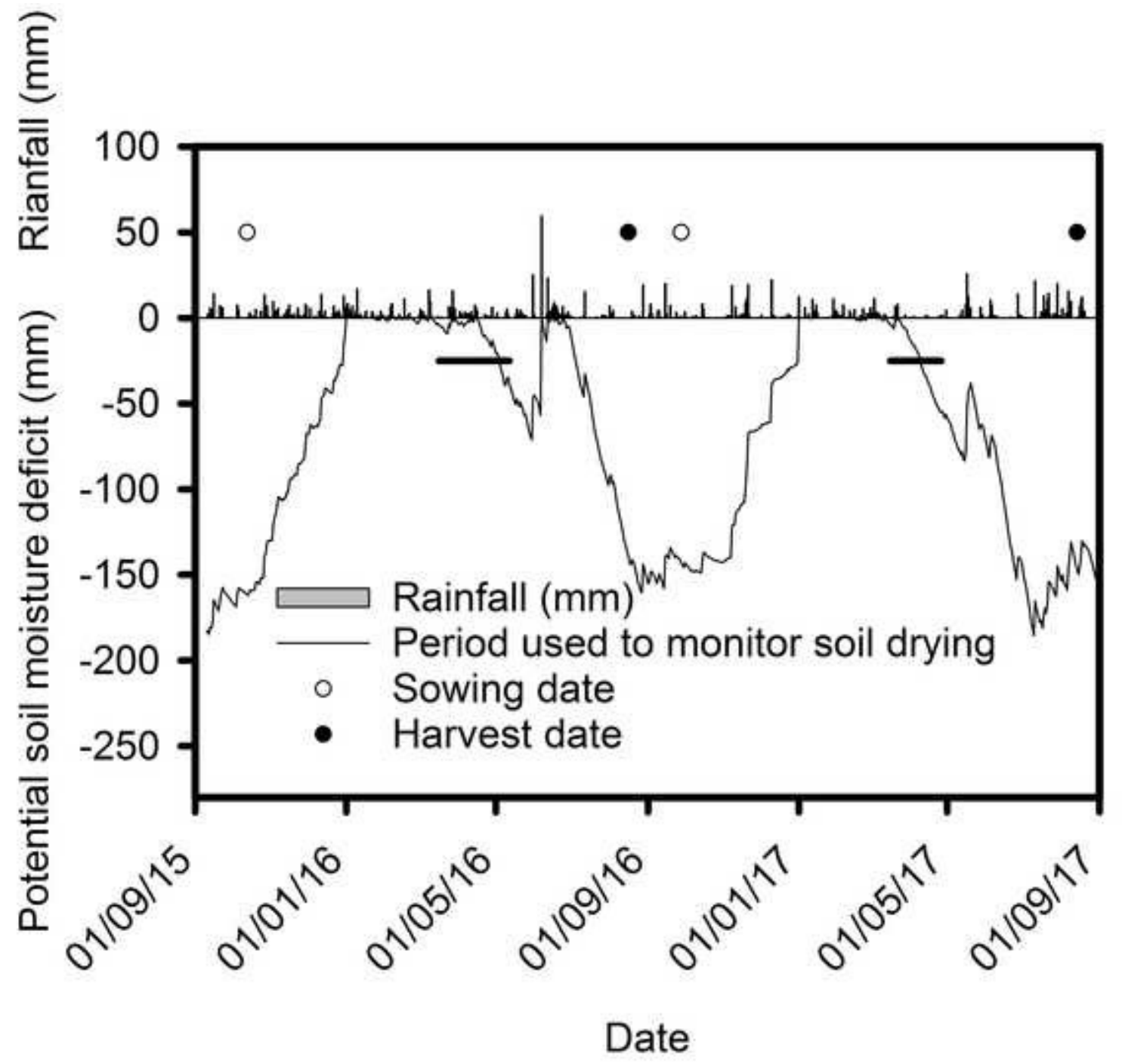



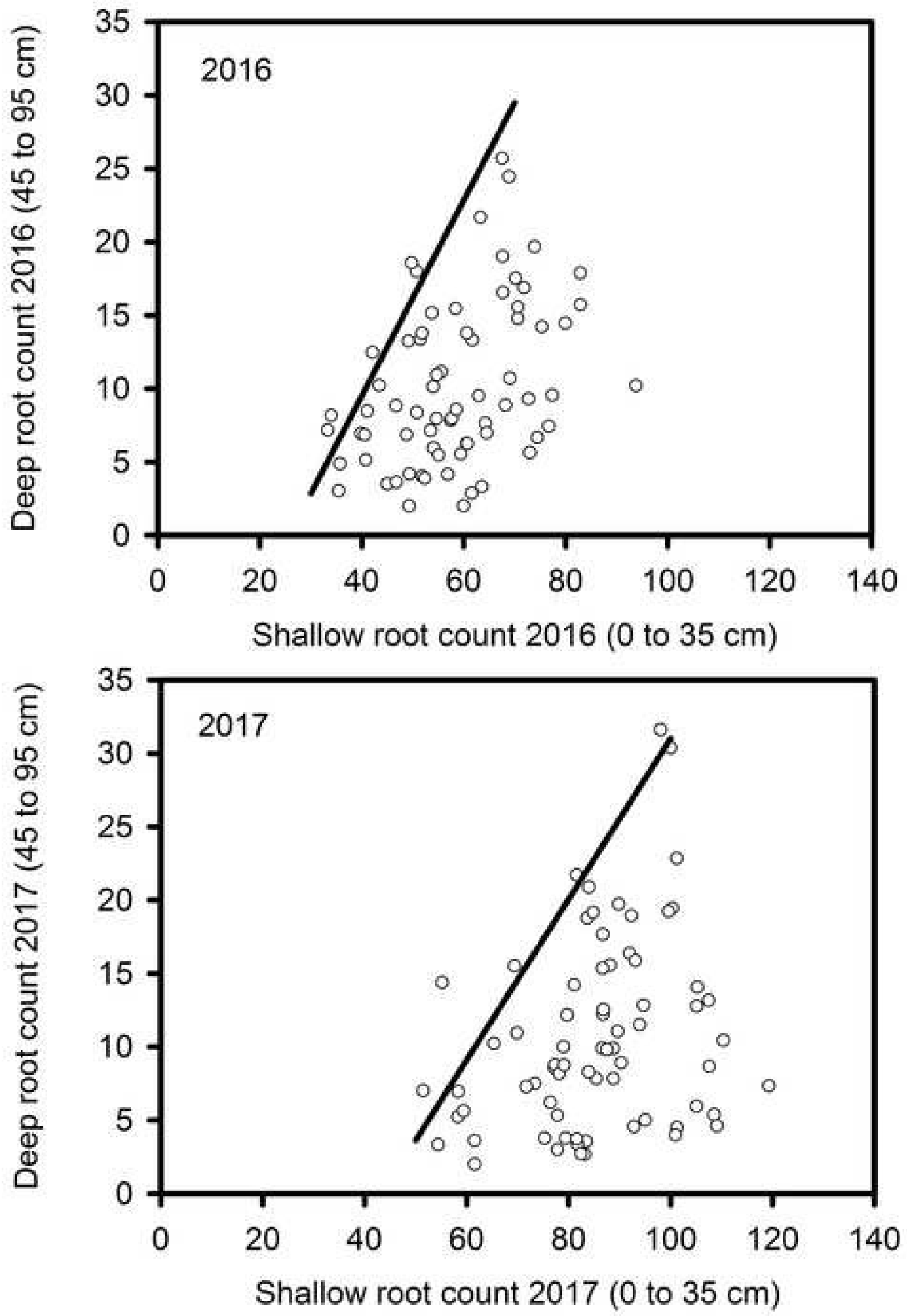


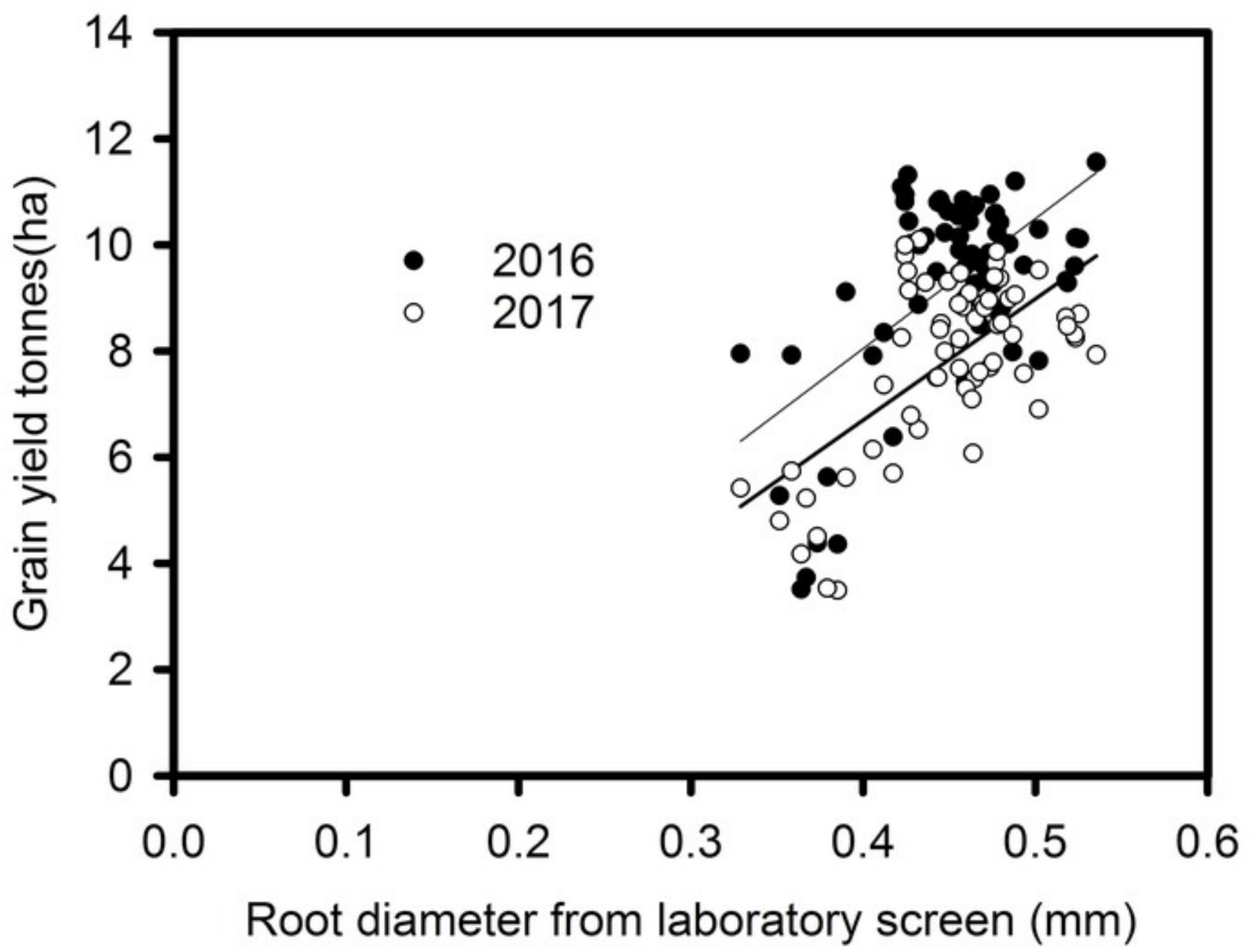


Supplemental data:

Wheat roots, rooting depth, root screens and yield

C. Bai ${ }^{1}$, Y. Ge ${ }^{1}$, R.W. Ashton ${ }^{1}$, J. Evans ${ }^{1}$, A. Milne ${ }^{1}$, M.J. Hawkesford ${ }^{1}$, W.R. Whalley ${ }^{1}$, M. A. J. Parry ${ }^{2}$, J., Melichar ${ }^{3}$, D. Feuerhelm ${ }^{3}$, P., Bansept Basler ${ }^{4}$, M., Bartsch ${ }^{5}$

${ }^{1}$ Rothamsted Research, Harpenden, Hertfordshire, AL5 2JQ, United Kingdom

${ }^{2}$ Lancaster Environment Centre, Lancaster University, Lancaster, LA1 4YQ, United Kingdom

${ }^{3}$ Syngenta Seeds Ltd., Hill Farm Road, Whittlesford, CB2 4QT, United Kingdom

${ }^{4}$ Syngenta SAS, Avenue Gustave Eiffel, 2800 Chartres, France

${ }^{5}$ Syngenta Crop Protection, Schaffhauserstrasse 101, 4332 Stein, Switzerland

1. Grouping of wheat lines

2. Leaf area index data 
Wheat line groupings

\begin{tabular}{|c|c|c|c|c|}
\hline \multicolumn{2}{|c|}{ Narrow root angle and thick roots } & \multicolumn{3}{|c|}{ Long seminal roots } \\
\hline Group 1 & Glasgow & Group 4 & Akteur & \\
\hline Group 1 & Hereford & Group 4 & \multicolumn{2}{|c|}{ Memory (tall) } \\
\hline Group 1 & Interet & Group 4 & \multicolumn{2}{|l|}{ Revelation } \\
\hline Group 1 & Shamrock & Group 4 & Scout & \\
\hline Group 1 & Tambor & Group 4 & Spark & \\
\hline Group 1 & Türkis & Group 4 & Syllon & \\
\hline & & \multicolumn{2}{|c|}{ Short seminal roots } & \\
\hline \multicolumn{2}{|c|}{ Wide angle and thin roots } & Group 5 & Armada & \\
\hline Group 2 & 5602HR:1- & Group 5 & Bermude & \\
\hline Group 2 & AC Unity & Group 5 & Kranich & \\
\hline Group 2 & Bologna 902109 & Group 5 & Meteor & \\
\hline Group 2 & Brennan & Group 5 & Player & \\
\hline Group 2 & BW445-101 & Group 5 & Premio & \\
\hline Group 2 & Elixer (tall) & Group 5 & Rialto & \\
\hline Group 2 & Jagger & Group 5 & Riband & \\
\hline Group 2 & Oakes & Group 5 & SY Epson & \\
\hline Group 2 & SY Gold & Group 5 & \multicolumn{2}{|c|}{ SY Moisson } \\
\hline Group 2 & SY Rowyn & Group 5 & \multicolumn{2}{|c|}{ SYNAB108101 } \\
\hline Group 2 & SY Southwind & & & \\
\hline \multicolumn{2}{|c|}{$\begin{array}{l}\text { Selected for contrasting shoot } \\
\text { phenology }\end{array}$} & \multicolumn{2}{|c|}{$\begin{array}{l}\text { Selected on the } \\
\text { basis of Breeder }\end{array}$} & \\
\hline Group 3 & Altigo & Group 6 & Avalon & \\
\hline Group 3 & Buenno & Group 6 & \multicolumn{2}{|l|}{ Bernstein } \\
\hline Group 3 & Cadenza & Group 6 & \multicolumn{2}{|c|}{ Cubanita (med) } \\
\hline Group 3 & Cellule & Group 6 & \multicolumn{2}{|c|}{ Dickens (med) } \\
\hline Group 3 & Cordiale & Group 6 & \multicolumn{2}{|c|}{ Edward (tall) } \\
\hline Group 3 & Expert & Group 6 & \multicolumn{2}{|c|}{ Gallant (med) } \\
\hline Group 3 & Gladiator & Group 6 & \multicolumn{2}{|l|}{ Helmond } \\
\hline Group 3 & Inspiration & Group 6 & \multicolumn{2}{|l|}{ Nudakota } \\
\hline Group 3 & JB Diego & Group 6 & \multicolumn{2}{|c|}{ Reflection (short) } \\
\hline Group 3 & KWS Kielder & Group 6 & \multicolumn{2}{|c|}{ Rht3 Mercia 2014} \\
\hline Group 3 & KWS Santiago & Group 6 & RhtC & \\
\hline Group 3 & Oakley & Group 6 & \multicolumn{2}{|c|}{ Skyfall (med) } \\
\hline Group 3 & RELAY & Group 6 & Line bL1 & \\
\hline Group 3 & Soissons & Group 6 & SY Ferry & \\
\hline Group 3 & SY Ovation & Group 6 & SY Flint & \\
\hline Group 3 & SY Wolf & Group 6 & line bl2 & \\
\hline Group 3 & Tobak (tall) & Group 6 & line bl3 & \\
\hline \multirow[t]{2}{*}{ Group 3} & Xi19 & Group 6 & line bl4 & \\
\hline & & Group 6 & line bl5 & \\
\hline
\end{tabular}




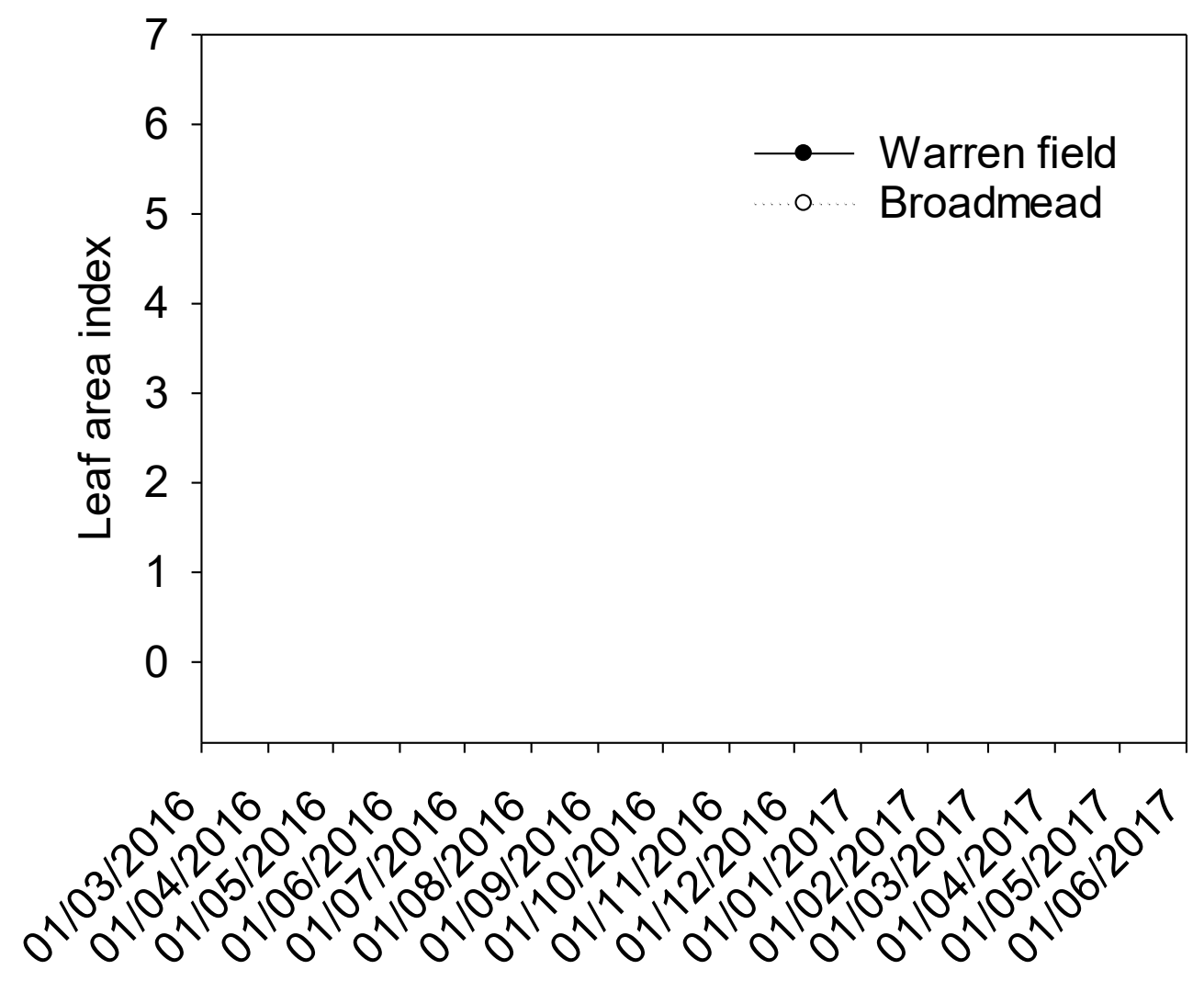

\section{Date}

Fig S1 Mean leaf area index in each of the seasons. 